\title{
Fuel Cell Technology Application For Dubai Rail Systems
}

\author{
Mohamad Y. Mustafa \\ Institute of Buildings, Energy and Material Technology \\ UiT The Arctic University of Norway \\ Narvik, Norway \\ mohamad.y.mustafa@uit.no
}

Bjørn E. Kanstad

Institute of Buildings, Energy and Material Technology

UiT The Arctic University of Norway

Narvik, Norway

\author{
Aziz Al-Mahadin \\ Aviation Engineering Department, DBM \\ Higher Colleges of Technology \\ Dubai, UAE \\ aalmahadin@hct.ac.ae
}

\author{
Raj K. Calay \\ Institute of Buildings, Energy and Material Technology \\ UiT The Arctic University of Norway \\ Narvik, Norway
}

\begin{abstract}
Heat engines, such as internal combustion engines, have significant adverse effects on the environment due to their heat and harmful emissions. In addition, they are dependent on energy from fossil resources, which are depleting rapidly and they are not being properly utilized due to the relatively low efficiency of heat engines usually expressed by Carnot's efficiency. The low temperature direct conversion process, in which hydrogen is chemically oxidized, is one of the best alternatives to heat engines. In this process, the heat emitted to the surroundings, or in driving the reaction, is kept to a minimum. This method would meet the pressing need of humanity to find power generation and utilization techniques that are more efficient and less harmful to the environment than conventional power generation methods. This will also help to conserve energy resources, and at the same time, protect the environment by reducing the amount of harmful emissions, and thermal loading i.e. greenhouse effects. In fact, the fuel cell technology can overcome these difficulties and pave the way for utilizing different sources of energy. This paper investigates the possibility of utilizing fuel cell technologies in Dubai public transportation and in particular the rail systems. This matter is critical for Dubai since it is one of the fastest growing cities. Recently Dubai has launched the Clean Energy Strategy, which aims to make Dubai a global centre of clean energy and green economy. The utilization of fuel cell technology is very important for Dubai since it has the potential to increase energy efficiency of the transportation sector, increase energy security, improve environmental quality, and position Dubai as a leading city in advanced rail transportation.
\end{abstract}

Keywords-Fuel Cell (FC); Dubai Roads and Transport Authority (RTA); Transportation; Proton Exchange Membrane (PEM); Rail Systems

\section{INTRODUCTION}

Dubai Tram and Rail network is an example of contemporary rail systems; it covers the main areas of Dubai with various modern stations distributed over the populationcongested areas. Dubai tram is considered as the first tram system outside Europe working on underground power supply all over the track without the need for cables to feed it with electricity, thus maintaining the aesthetic appearance of the city and reducing the amount of pollution in the urban area. The rail system in Dubai has the potential to become a world leader in utilizing hydrogen and fuel cell (FC) technologies. On a global scale, the transport sector with its nearly $100 \%$ dependence on oil has for years been an interesting field of development for hydrogen technology because of the possibility to use hydrogen produced from fossil and renewable energy sources. With the currently increasing concerns regarding the security of energy supply and growing awareness of the problem of climate change, the interest for hydrogen is increasing at an unprecedented rate. However, until now, most interest has been concentrated on the application of hydrogen technology in road vehicles, where a considerable number of car and bus prototypes have been presented by the world leading automobile producers.

Today, railways are under pressure to decrease their overall emissions, especially carbon [1]. Furthermore, a reduction of other combustion emissions at the point-of-use, such as; particulate matter and nitrogen oxides, is required by law in the European Union and the USA [2]. Currently, world railway industries are concerned about the future supply of petroleum, its prices, the environmental impacts, and hence the sustainability of the whole sector. In addition to the above concerns, audible noise that is emitted from railway vehicles, for example from diesel combustion or cooling fans, has to be reduced and for new trains maximum limits apply.

Railways have partially responded to these challenges in autonomous traction in two ways [1]:

- Through electrification programs, particularly in Europe.

- The investigation of innovative alternative propulsion methods for lines that cannot be electrified economically. 
Interest in hydrogen as an energy source for railway systems has so far been very moderate. This can be attributed to the fact that electrification is a handy and economical alternative that does not rely entirely and directly on fossil energy. Electrification of railways is a solution where grid electricity generated from various sources is efficiently transmitted to the driving wheels of electrical trains. Electric propulsion is quite an attractive solution because it eliminates, or at least reduces harmful emissions at the point-of-use and provides better operating characteristics. Conversely, steam power allows the operation of trains anywhere on the network without the need for expensive electrification infrastructure [3], [4]. On the other hand, diesel-electric traction combines the advantages of electrification and steam power; it provides autonomous traction with fewer emissions than steam and it has the superior operating characteristics of electric propulsion. However, the overall power is still limited by the on-board prime-mover. It should also be noted that, in the case of diesel and steam engines, the weight of the power plant and the fuel add considerably to the weight of the train system. While in the case of electric trains, the weight is significantly reduced as the train does not need to carry any fuel on-board, and the weight of the power plant is much lighter than the diesel and steam traction systems. Furthermore, traction power available in the case of electric trains is only limited by the size of the electric motor of the traction system.

\section{ELECTRICAL RAIL SYSTEMS}

Large-scale electrification projects of railway networks are usually realised by governments. This is mainly due to the fact that private companies do not have the capacity to undertake such projects due to economic considerations, unless they were supported financially by their respective governments. Furthermore, individual companies cannot address the longterm macro-economic benefits, that affect the community as a whole, such as reduction of emissions, diversification of fuel sources, and investments aimed at solving employment problems at times of recession [3].

One important reason for electrification is the security of energy supply. For example, electrification is usually considered as a viable solution preferred over steam traction for countries that did not have a domestic supply of coal as steam traction was primarily dependent on coal. This case is also true with regards to diesel especially in the second half of the 20th century. Therefore, countries that had a domestic supply of diesel such as the USA, employed diesel traction, whereas countries with limited petroleum resources had a tendency towards electrification, as domestic energy sources, such as coal and hydropower, could be utilized [5]. Furthermore, the railways in those countries were primarily state-owned, allowing favourable funding conditions for rail electrification. In general, it can be stated that electrification is generally employed for reasons pertaining to energy security and to enable the utilization of domestic energy sources, or to address specific operational problems, such as emissions at the pointof-use; and in some circumstances to increase network capacity and performance [1].

In addition to the high cost of electrification infrastructures, as in Fig. 1, the rail catenary wires pose a

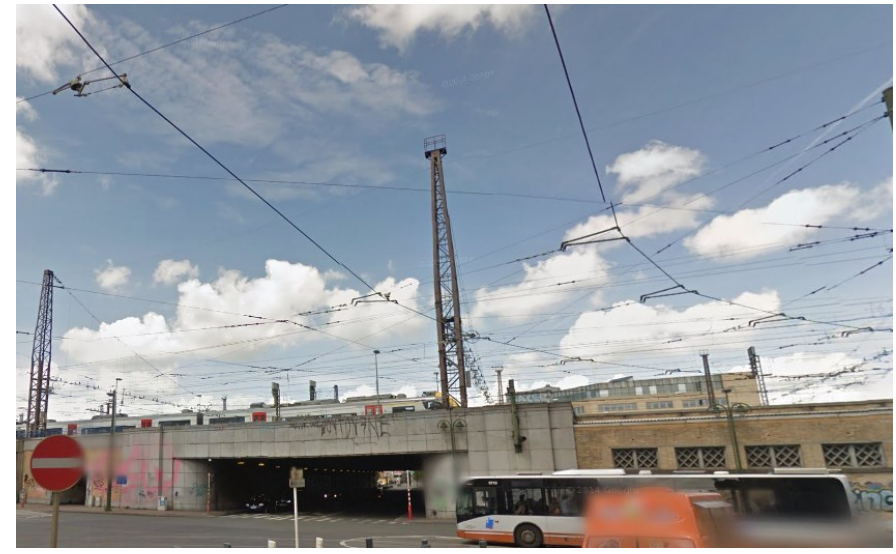

Fig. 1. Main line overhead electrification infrastructure in brussels (author's collection, 2017).

visual annoyance in city centres. This has incited alternative solutions, such as ground level electrification as in Dubai, and in Bordeaux, or hybrid trams with on board energy storage in the form of battery-packs as in Niece [6]. The trams in Nice can operate either from overhead electrification infrastructure or from the on-board batteries in the non-electrified sections of the rail system. However, in the long term, fuel cells are expected to replace heat engines as a more efficient and environmentally friendly energy converter. Hydrogen as fuel is expected to replace fossil fuels in everyday utilization.

The remaining fossil fuels, which are basically hydrocarbons, could be treated to separate carbon from hydrogen under controlled conditions in order to utilize hydrogen in fuel cells for zero carbon generation of energy. The captured carbon can be directed for use in other industrial processes, thus reducing the amounts of carbon emitted to the atmosphere.

This study considers the conversion of the rail system in Dubai from an electrified system into FC system run on hydrogen as the primary fuel. The current RTA public transportation rail system depends on electricity generated from fossil fuel sources, while the proposed one depends on hydrogen fuel generated from fossil and renewable energy sources which are emission free or involving carbon capture technologies. The study will investigate the pros and cons of fuel cell technology in the context of Dubai rail system and is designed to pave the way for more comprehensive investigations and feasibility studies.

\section{A Study CASE Of The First Hydrogen Driven PASSENGER TRAIN}

Conversion to hydrogen does not require investments in infrastructure, but only in new rolling stock. Due to the fact that hydrogen technology is fairly new, it is not easy to estimate the potential costs of this conversion. However, it can be generally stated that hydrogen technology is more expensive than diesel based solutions and conventional electrification under current conditions. Nevertheless, this situation is expected to change fairly soon, with the demonstration of the first train powered with a hydrogen fuel cell by Alstom passenger train Coradia iLint [7]. This example can be taken as 
a proof of concept of the first passenger train worldwide which utilises a hydrogen fuel cell to produce electrical power for the traction. The Coradia iLint is a zero-emission train including noise emissions; hence it is absolutely silent and only emits steam and condensed water. The train is unique and combines different innovative elements such as: a clean energy conversion, flexible energy storage in batteries, and a smart management of the traction power and available energy. It enables sustainable train operation while maintaining high train performance. This development marks a significant milestone in environmental protection and technical innovation.

The first test runs of the Coradia iLint fuel cell passenger train were successfully performed on Tuesday 14th of March 2017. The test runs were continued for four-weeks in Salzgitter (Germany) in order to confirm the stability of the energy supply system based on coordinated interaction between the drive, the fuel cell and the battery of the vehicle. The runs also included testing the braking power to check the interface between the pneumatic and the electric brake. The Coradia iLint will perform its first passenger test runs on the Buxtehude-Bremervörde-Bremerhaven-Cuxhaven (Germany) route beginning of 2018 . The dynamic tests were performed at Salzgitter plant at $80 \mathrm{~km} / \mathrm{h}$ and in Velim (Czech Republic) at up to $140 \mathrm{~km} / \mathrm{h}$, which is the maximum speed of the Coradia iLint. For the purpose of the tests, a mobile filling station has been erected in Salzgitter to pump gaseous hydrogen into the pressure tanks atop of the train [8].

\section{TeChNOLOGY SCREENING OF FC AdVANCEMENTS}

Future hydrogen trains utilising FC-power systems are very much similar to electric trains as they considerably use similar elements and system solutions. Furthermore, a hydrogenfuelled train will be able to move autonomously without the need for electric lines and different electrical systems. Furthermore, noise problems generated by IC engines and motor generator sets could be eliminated, thus reducing noise build up in urban areas and city centres and improving public acceptance of hydrogen trains and infrastructure.

A hydrogen infrastructure can be shared by both rail and road transportation, leading to expansion of the hydrogen market and supply chain that can serve both train systems and land vehicles. A hydrogen supply chain and production facility will definitely give great synergy benefits and the possibility to demonstrate the FC train as an element in a future sustainable transportation structure with hydrogen as an important energy carrier [9]. Hydrogen for transport can be used either in an internal combustion engine (ICE) or in a fuel cell (FC) solutions. The ICE solution uses a technology and a system very close to the diesel-powered trains. This option is not recommended due to its lower energy efficiency and inferior environmental impacts.

Fuel cell technology utilizing hydrogen fuel has great advantages compared with the internal combustion engine (ICE) technology. The basic principle of a fuel cell is a chemical reaction between hydrogen and oxygen that produces power and heat and pure water as a by-product. The fuel cell is an electrochemical energy conversion device that converts the chemical energy of its inputs to electrical energy in a chemical reaction, without the need for combustion, thus eliminating the high-energy losses and harmful emissions, which usually accompany the combustion process. Fuel cell technology has many advantages over IC engines; it has been tested and validated to be one of the main energy converters that can be utilized due to its efficiency, high energy density, low noise and pollutant emissions. Every fuel cell has an anode, a cathode and an electrolyte, which carries electrically charged particles from one electrode to the other, Fig. 2. It also has a catalyst that speeds the reactions at the electrodes. Fuel cells are usually assembled into a stack to customise and boost their power output. They usually generate direct current, which can be manipulated and converted to alternating current. There are five main types of fuel cells classified with respect to the electrolyte used in the fuel cell, however, the primary fuel used in most types is hydrogen, but other types of ions can also be used in some fuel cells. Hydrogen is produced from various energy sources including: renewable energy, fossil fuel, coal, gas and many others. Its production and use give near zero greenhouse emissions if proper emission control methods were employed and can be utilized for all sectors including transportation [10].

Due to the low temperature electrochemical conversion process utilised in fuel cells, their efficiency is much higher than internal combustion engines, which are primarily heat engines that emit huge amounts of useful heat during their operation. This does not only reduce the amount of fuel used in the fuel cell, but also reduces heat emissions and other pollutants emitted by the IC engines and consequently reduces the heating load and the greenhouse gases emitted to the environment. This efficiency can be further optimized through using regenerative braking systems to store the braking energy of the train. Based on screening of FC technologies, their advantages for the train operators can be summarized in the following points:

- Higher efficiency leading to savings in fuel costs, better performance and less weight of components.

- Fewer moving components leading to reduced maintenance cost and shorter down time.

- Elimination of complex emission control systems.

- $\quad$ Reduced noise and emissions, which leads to better public acceptance and higher standards of train service. This is an advantage for passengers, local community and train operators.

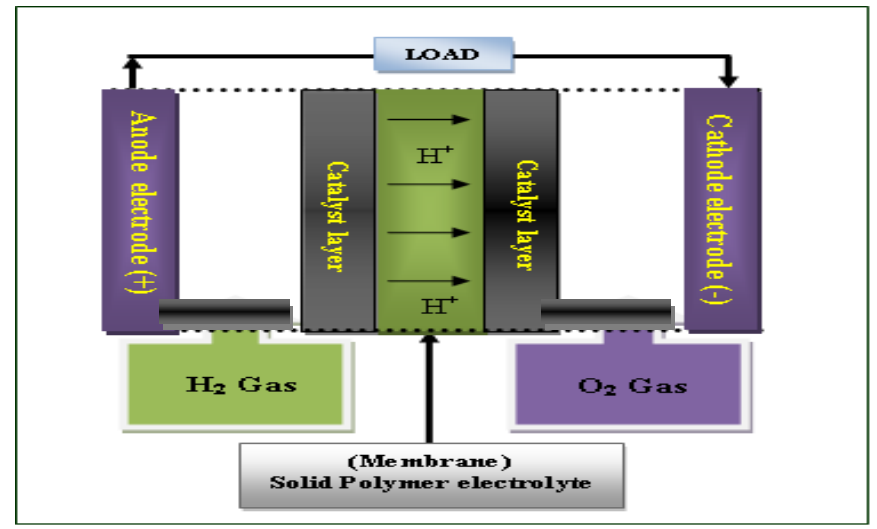

Fig. 2. Schematic of a low temperature PEM Fuel Cell [10]. 
While considering the RTA mission that calls for innovative and sustainable transportation system [11], the main advantages of utilising hydrogen fuel cells in Dubai rail systems have been discussed. Then it is important to demonstrate that hydrogen is a suitable energy carrier for railway traction by considering the following elements:

- Various sources can be utilised for the production of Hydrogen and not only fossil fuel.

- Power production based on Hydrogen technology leads to higher reductions of greenhouse gas emissions compared to diesel based systems, in addition to the elimination of emissions at the pointof-use.

- From the technical point of view, it has been proven that Hydrogen-powered systems can be easily implemented for railway traction vehicles.

- Hydrogen fuel cell systems are characterised by their high duty-cycle efficiencies. As such, the performance of hydrogen vehicles is convenient for the provision of railway services.

- A hydrogen-based system can replace or retrofit an existing diesel system or electrical drive system with increased performance, better efficiency leading to a reduction of energy consumption, and much lower emissions.

- Due to the high power density of fuel cells, they provide a compact solution as compared to IC engines, and as such, the necessary hydrogen drivesystem components can be accommodated within the space available on the train, without exceeding vehicle mass restrictions [12].

\section{BRIEF COST AND LifETIME ANALYSIS}

One of the most appropriate FC technologies for transportation systems is the Proton Exchange Membrane (PEM), Fig. 2. The expected cost of a PEM fuel cell system, considering an $80-\mathrm{kWnet}$ automotive and based on current technology as a bench-mark, is approximately $265 € / \mathrm{kW}$ $(\$ 280 / \mathrm{kW})$ when manufactured at a volume of 20,000 units/year. This could be compared with a price for "train size" ICE unit $(300 \mathrm{~kW})$ of around $65 € / \mathrm{kW}$ and a complete drive unit price of $245 € / \mathrm{kW}$ [8]. Obviously, it can be observed that the cost of hydrogen fuel cells is approaching the cost of ICE based train drive unit.

The lifetime for fuel cell stacks is presently approaching 20,000 to 40,000 hours depending on application and type of the fuel cell, as the technology of fuel cells is developing at a high rate. The lifetime of a diesel engine for trains is around 15000-20000 hours before main maintenance. The fuel cell technology has the potential to over-live the traditional diesel engine and it gives more savings in maintenance and downtime due to its simplicity and absence of moving parts, in addition to savings due to increased efficiency and reduced fuel consumption [8].

For comparison, the costs of electrification depends mainly on the track length, but they can also depend on local conditions. Based on projects from Denmark and other
European countries, the estimate for a double track line is $€ 1$ 1.2 million EUR per km; obviously, this cost is high. The key factor, when comparing the cost for conversion of an existing railway line to hydrogen, is the relation between the track length considered and the traffic intensity on the line. The overall cost has to be evaluated along with other advantages including environmental and safety considerations.

\section{A. Proposed Hydrogen Train configuration}

In this paper, the initial consideration will be for the case of converting an electric locomotive to hydrogen. Electric powered trains use electro motors placed close to the driving wheels. As such, they represent an excellent option for utilizing hydrogen fuel cells because electricity produced by the fuel cells can be used to run the existing drive motors. An example of Hydrogen Fuel Cell Locomotive is shown in Fig. 3.

In a hydrogen train, the required electric power will be produced by a fuel cell stack and therefore overhead or underground lines will be eliminated. Instead, storage for the hydrogen and a battery-super capacitors hybrid system (i.e. for storage of braking energy and electrical energy for transient operation) will be needed. Furthermore, the transformers used in the train setup will be smaller. The existing electric traction system can be used in the hydrogen train while the electric transformers and current collector can be replaced by the fuel cell system and hydrogen storage.

The hydrogen storage does not need regular maintenance and it is recommended to place it on the roof, as this allows for harmless upward dissipation of hydrogen in the event of a leak and minimizes the likelihood of damage from events such as derailment, track debris, and impact from yard traffic such as fuelling trucks, etc.

However, this choice could be restricted by the allowable height of the trains in relation to tunnels and other regulations. Initial studies indicate that Dubai rail system can allow on-roof installation, however, this is not a critical issue and other locations can be considered since hydrogen storage technology is well developed and allows hydrogen cylinders to be placed with various setups. Parts of the fuel cell system that will need some maintenance can be located between the bogies in the space designed for the electrical transformer as indicated in Fig. 4.

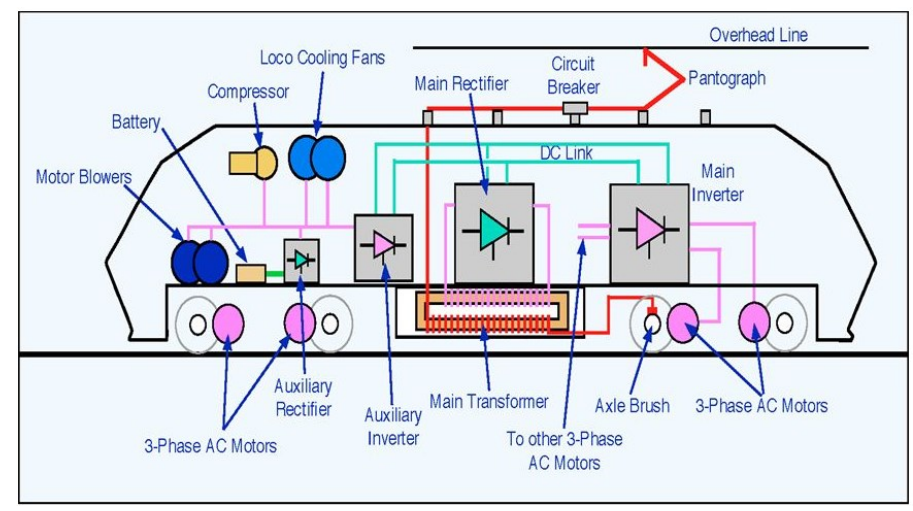

Fig. 2. Components of an electrical - AC locomotive [4] 


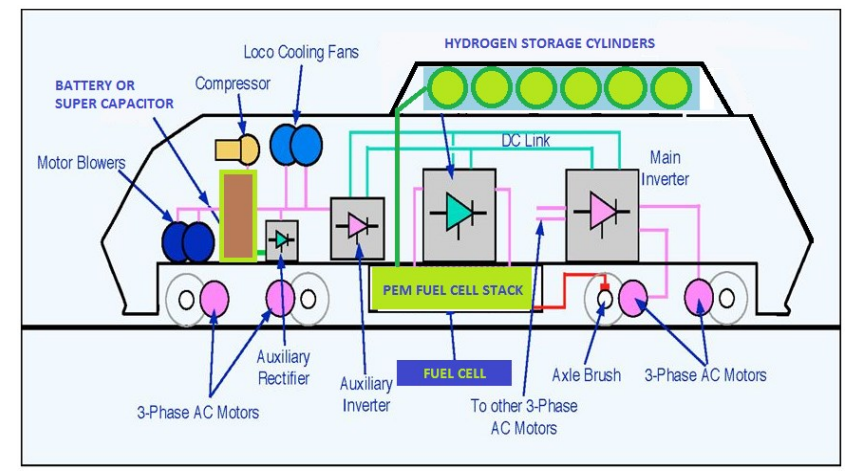

Fig. 3. Components of a proposed hydrogen FC Locomotive [4].

Most currently used passenger electric trains are Electric Multiple Units (EMUs), in which each carriage is selfpropelled using electricity as the motive power, such as the case in Dubai. An EMU requires no separate locomotive as the electric traction motors are incorporated within one or a number of the carriages. The same approach illustrated in Fig. 4, can be followed in placing the fuel cell and other components on EMUs.

One example of EMU conversion to Hydrogen Fuel Cell is the Bombardier Talent 3 car electrical unit. Fig. 5, shows a proposal for installing hydrogen pressure storage, fuel cells and Energy Saver storage on a Bombardier Talent 3 EMU. In this set up, the electrical powered train is normally equipped with a heavy electrical transformer behind the front bogies. The hydrogen storage is placed on the roof over the front bogies as replacement of current collectors. The fuel cell system is located behind the front bogies instead of the transformer. Super capacitor batteries for energy saving system can fit under the low floor area and can be positioned in accordance with best axle load distribution [8].

An alternative configuration was offered by Bombardier on their FLEXITY Link. In this set up, the electric powered train is normally equipped with a heavy electrical transformer on the middle between the bogies. The hydrogen storage is placed on the roof over the front bogies as a replacement of the current collectors. The fuel cell system is located in the space where the electrical transformer were placed. This configuration is shown in Fig. 6, [8]. Those examples indicate that converting existing EMUs to fuel cell vehicles is possible without the need for major modifications.

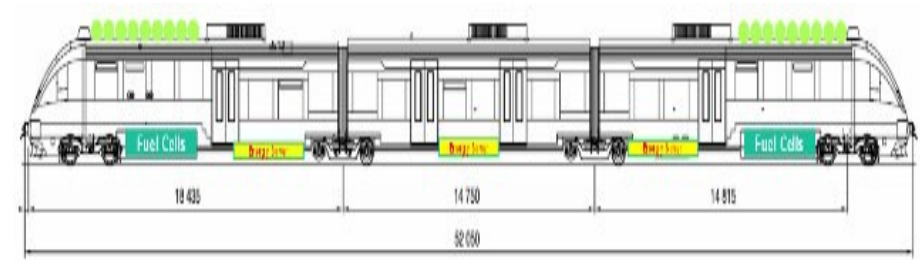

Fig. 4. Proposed EMU conversion to Hydrogen Fuel Cell by the Bombardier Talent 3 car electrical unit [8] Hydrogen storage is shown in light green, fuel cells in dark green and battery and super capacitors in yellow.
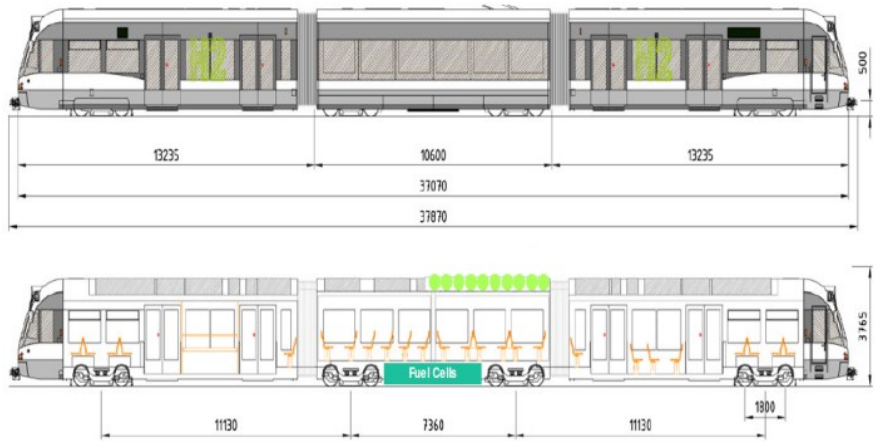

Fig. 5. Alternative Proposed EMU conversion to Hydrogen Fuel Cell by the Bombardier FLEXITY Link car electrical unit [8].

\section{HYDROGEN POWERED TRAIN SWOT ANALYSIS}

At this stage, it is important to carry out an initial SWOT analysis of hydrogen FC technology adaptation for the current Dubai rail system in order to highlight the strengths, weaknesses, opportunities and threats. This can also help Dubai rail system management to identify the internal and external factors that will affect their decision for adaptation of the proposed transformation of the current system into hydrogen FC system.

\section{STRENGTHS}

- Provide a reduction in energy consumption due to higher efficiency compared with diesel engine.

- Reduce emission and harmful greenhouse effect.

- Reduce local air and noise pollution compared to diesel.

- An attractive alternative to electrification of trains on remote railways with light traffic density.

- Reduce maintenance cost due to fewer moving parts of the fuel cell system.

- Reduce the need for complex emission control systems.

- Eliminate visual pollution and dangers from electric wires in cities and populated areas.

- Availability of sufficient storage space on the roof of train wagons.

- Possibility of fast refuelling.

- Possibility of autonomous traction locomotives.

\section{WEAKNESSES}

- Cost of Hydrogen storage.

- Cost of PEMFC solutions.

- Lifetime and durability of fuel cell systems.

- System too light - but can easily be ballasted. 


\section{$>$ OPPORTUNITIES}

- Increase energy security for rail transportation by reducing dependency on fossil fuels.

- Relatively few refueling points (compared to road vehicles) making the move from diesel to hydrogen easier in train applications than road.

- The move to hydrogen-based fuel will eliminate damage and pollution in local environment currently caused by fossil fuel.

- Long term decrease in hydrogen price.

- Long term decrease in battery price.

- Potential for stricter air quality regulations.

- Possibility of technological breakthrough in Hydrogen and fuel cell technology leading to better prices and performance improvement.

\section{$>$ THREATS}

- Lack of regulations concerning Hydrogen and fuel cells in the locomotive sector.

- Lack of infrastructure.

\section{ADVANTAGES OF FC RAIL SYSTEMS FOR DUBAI}

Dubai government follows a vision to create a world-class city. It is committed to promote the delivery of sustainable clean energy with excellent level of reliability, efficiency and safety. To achieve that, Dubai needs to adapt new technologies to make an efficient use of the available resources in order for the urban environment to become more liveable, functional and competitive. Fuel cell technology can support this strategy by being utilized in all energy sectors and most importantly the transportation sector.

As a matter of fact, Dubai Roads and Transport Authority (RTA) has pledged through its announced mission to develop integrated and sustainable transportation systems by adapting technologies and innovative approaches. This is very essential due to Dubai's fast and comprehensive growth [11]. It is clear that hydrogen FC technology is an option, which can transform the current transportation rail system without total disruption of the existing resources and processes. Transforming the current Dubai rail systems to hydrogen FC can have many advantages including:

- Economical savings on the long run.

- Environmentally friendly, therefore, ideally suited for use within cities like Dubai.

- Enhanced energy security since fuel cells do not need conventional fuels.

- Generation of fuel can be distributed and does not have to be grid-dependent.

- Requires less maintenance and less management.

\section{SUMMARY AND RECOMMENDATIONS}

In this work, an overview of the current rail systems in Dubai and elsewhere were discussed in relevance to the pressing demands for reducing greenhouse gas emissions and for increased energy efficiency in order to reduce fuel consumption and cost of travel for passengers. In order to address those challenges, railways have two options: electrification or the implementation of innovative alternative propulsion methods for lines that cannot be electrified economically.

Electrification of railways is an attractive solution because it reduces harmful emissions at the point-of-use and provides better operating characteristics. However, it has its limitations and social impacts such as: pollution at the power generation location in case fossil fuels or coal were used as the primary source of energy, the aesthetic impact of catenary cables especially in urban areas, and the high cost of electrification.

In this work, conversion of the Dubai rail system to hydrogen fuel cell power traction was investigated. This is in line with the vision of Dubai government to create a world class city based on new technologies and innovations. A hydrogen powered rail system can offer Dubai various advantages such as low noise, reduced harmful emissions and better power efficiency independent of fossil fuels. This study investigated a brief life cost analysis and discussed possible configurations of the proposed system. A SWOT analysis was done for hydrogen FC technology adaptation for the current Dubai rail system in order to assist Dubai rail system management to identify the internal and external factors that will affect their decision in this regard.

The authors recommend and encourage RTA to consider the conversion of Dubai Rail system to hydrogen fuel cell technology, as this would be a breakthrough in rail systems worldwide and will boost the reputation of Dubai as the leading contemporary city in the world. Further detailed studies in this matter are also recommended.

\section{CONCLUSION}

While considering RTA mission and vision and based on this investigation, it is concluded that there is a great opportunity for Dubai to renovate and transform its railway system by utilizing hydrogen fuel cell technology. This transformation will have great positive impacts on the city both environmentally and economically on the long run. The current FC Technology is mature enough to be adapted for such application and the near future FC advancements and horizons are even more promising. It was intended that this paper will pave the way for more comprehensive investigations and feasibility studies.

\section{ACKNOWLEDGMENT}

The authors convey their gratitude to the support and encouragements received from Dubai Men's College, the Higher Colleges of Technology, from Dubai Roads \& Transport Authority (RTA), UAE, and UiT the Arctic University of Norway, Norway in conducting this research. 
This work is also supported by the EU NSR HYTREC2 Hydrogen transport economy project.

\section{REFERENCES}

[1] I. E. Agency, "Railway Handbook 2012 Energy Consumption and CO2 Emissions”, Paris, France, 2008.

[2] Milieu Ltd, Danish National Environmental Research Institute and the Centre for clean Air Policy, "Assessment of the effecxtiveness of European Air Quality policies and measures", European Union, Brussels, 2004.

[3] Hollingsworth, B., \& Cook, A. (1996), Das Handbuch der Lokomotiven. Augsburg: Bechtermuenz Verlag im Weltbildverlag GmbH., Berlin, Germany, 1996.

[4] Schafer, M., Welsh, J., \& Holland, K., "The American Passenger Train", St. Paul: MBI Publishing Company., 2001.

[5] C. Kerr, "Kerr, C. (1951). The economic factors which influence dieselization and electrification", Electrical Engineering, 70(10), 867-869. doi: 10.1109/ee.1951.6436861, vol. 70, nr. doi: 10.1109/ee.1951.6436861, pp. 867-869, 1951.

[6] Hoffrichter, A., Silmon, J., Schmid, F., Hillmansen, S., \& Roberts, C., "Feasibility of discontinuous electrification on the Great Western Main Line determined by train simulation", Proceedings of the Institution of Mechanical Engineers, Part F: Journal of Rail and Rapid Transit,, vol. 227(3), nr. doi: 10.1177/0954409712461341, pp. 296-306., 2013.

[7] D. Fowler, "Alstom eyes Liverpool hydrogen train trials", The Engineer, vol. 9, nr. Registered in England No: 1595235, pp. 1-3, 2017.

[8] H. R. County, "The Hydrogen Train Feasibility Study", H2 Logic ApS, Copenhagen, 2006.

[9] C. Santoro, C. Arbizzani, Benjamin Erable, Ioannis Ieropoulos, "Microbial fuel cells: From fundamentals to applications", Journal of Power Sources , vol. 356 , nr. 1, pp. 225 - 244, 2017.

[10] M. Y. Mustafa, "Implications of the Progressive Transition to Hydrogen Economy", Romanian Journal of Building Services, vol. 1, nr. 3, pp. 1-6, 2015. , p. 1/6, 2015.

[11] RTA, "Mission of RTA", The Official Monthly Magazine of Dubai's Roads and Transport Authority, vol. $70,2014$.

[12] A. Hoffrichter, "Hydrogen As An Energy Carrier For Railway Traction", University of Birmingham, Birmingham, 2013. 